\title{
Impact of medical consultation frequency on risk factors and medications 6 months after
} acute coronary syndrome

\author{
Karice Hyun ${ }^{a}$, David Brieger ${ }^{b, c}$, Clara K Chow ${ }^{a, d}$, Marcus IIton ${ }^{e}$, \\ David Amos ${ }^{\dagger}$, Kevin Alford', Philip Roberts-Thomson ${ }^{h}$, Karla Santoa, \\ Emily R Atkins ${ }^{a}$ and Julie Redfern ${ }^{a, i}$
}

a The George Institute for Global Health, Sydney Medical School, The University of Sydney, NSW, Australia

${ }^{b}$ Cardiology Department, Concord Hospital, Sydney, NSW, Australia c Sydney Medical School, The University of Sydney, NSW, Australia ${ }^{d}$ Cardiology Department, Westmead Hospital, Sydney, NSW, Australia

\begin{abstract}
e Cardiology Department, Royal Darwin Hospital, NT, Australia ${ }^{\dagger}$ Cardiology Department, Orange Health Service, NSW, Australia ${ }^{9}$ Cardiology Department, Port Macquarie Base Hospital, NSW, Australia

${ }^{\mathrm{h}}$ Cardiology Department, Royal Hobart Hospital, Tasmania, Australia Corresponding author: jredfern@georgeinstitute.org.au
\end{abstract}

\section{Article history}

Publication date: January 2016

Citation: Hyun K, Brieger D, Chow CK, Ilton M, Amos D, Alford K, et al. Impact of medical consultation frequency on risk factors and medications 6 months after acute coronary syndrome. Public Health Res Pract. 2016;26(1):e2611606. doi: http:// dx.doi.org/10.17061/phrp2611606

\section{Key points}

- Initiatives aimed at supporting primary care to better enable delivery of optimal prevention services are important

- Patients with acute coronary syndrome visited their general practitioner relatively frequently in the 6 months after hospital discharge

- Patients with acute coronary syndrome who saw a general practitioner in the 6-month period had significantly higher rates of participation in cardiac rehabilitation, receipt of dietary advice and prescription of cardioprotective medications

- Seizing these opportunities to engage, manage and support patients is important for strengthening prevention in primary care

\section{Abstract}

Objective: Initiatives that support primary care to better enable delivery of optimal prevention services are of great importance. The purpose of this study was to examine the frequency of medical consultations by patients with acute coronary syndrome (ACS) in the 6 months after hospital discharge and to determine whether the frequency of visits was associated with differences in lifestyle, clinical measures and medication prescription.

Methods: We conducted a retrospective subgroup analysis of data collected in the Cooperative National Registry of Acute Coronary Care, Guideline Adherence and Clinical Events (CONCORDANCE), which is an ongoing (prospective) clinical initiative providing continuous real-time reporting on the clinical characteristics, management and outcomes of patients admitted to Australian hospitals with ACS. We compared clinical measures, medications, smoking status and receipt of cardiac rehabilitation with frequency of medical consultations 6 months after hospital discharge.

Results: Patients with ACS visited their general practitioner (GP) a mean of $4.4( \pm 3.8)$ times and their cardiologist $1.2( \pm 0.9)$ times in the 6-month period after their index admission. Patients who saw a GP in the 6-month period had significantly higher rates of participation in cardiac rehabilitation, receipt of dietary advice and prescription of cardioprotective medications. Factors associated with increased frequency of GP visits were older age groups (oldest fourth vs youngest fourth incidence rate ratio (IRR) 1.08; 95\% Cl 1.01, 1.14), being female (male vs female IRR 0.83; 95\% Cl 0.80, 0.86), diagnosis of ST-segment elevation myocardial infarction (STEMI) (STEMI vs non-STEMI IRR 1.08; 95\% Cl 1.04, 1.13; STEMI vs unstable angina IRR 1.01; 95\% Cl $0.95,1.06)$, being a current smoker (IRR 1.09; 95\% Cl 1.05, 1.15), history of cardiovascular disease (IRR 1.06; $95 \% \mathrm{Cl} 1.01,1.12)$, history of diabetes (IRR 1.25; 95\% Cl 1.21, 1.31), in-hospital inpatient revascularisation (IRR 0.95; 
95\% Cl 0.91, 0.99), receipt of cardiac rehabilitation referral (IRR 0.93; 95\% CI $0.89,0.97)$, and discharged on four or more out of five indicated medications (IRR 1.04; 95\% Cl 1.00, 1.08).

Conclusion: The majority of ACS survivors in this study saw their GP frequently and their cardiologist at least once during the 6 months after index admission. Seizing these opportunities to engage, manage and support patients is important for strengthening prevention in primary care.

\section{Introduction}

Noncommunicable diseases, including cardiovascular disease (CVD), cancer, chronic respiratory diseases and diabetes, are responsible for two-thirds of deaths globally and their prevention is a priority of the World Health Organization (WHO). ${ }^{1}$ WHO has set a target of $25 \%$ relative reduction in risk of mortality from CVD, cancer, diabetes or chronic respiratory diseases by 2025. ${ }^{1}$ Objectives for reducing the preventable burden include strengthening national capacity, strengthening health systems and promoting research. ${ }^{1,2}$ To achieve these goals, strengthening prevention of CVD is currently a priority area in Australia and across the world. . $^{2,3}$

Secondary prevention strategies target individuals with existing disease and aim to reduce their risk of future events. Cardiovascular disease includes coronary heart disease, heart failure, cardiomyopathy, congenital heart disease, peripheral vascular disease and stroke. ${ }^{4}$ In the case of CVD, secondary prevention is recommended in all the major national and international guidelines. $5,6,7,8$ Taken together, these guidelines recommend use of evidence based medications, risk factor management, lifestyle modification (including physical activity, diet and smoking cessation), screening for psychosocial factors, and providing education, monitoring and support. However, despite the guidelines, uptake of, and adherence to, secondary prevention medicines ${ }^{9}$ and lifestyle recommendations is low. ${ }^{10}$ Referral to, participation in and completion of structured secondary prevention programs (such as cardiac rehabilitation) is also suboptimal, with only $15-30 \%$ of eligible patients participating. ${ }^{11,12} \mathrm{~A}$ recent observational study, the SNAPSHOT ACS audit in Australia and New Zealand, demonstrated that only about one-quarter of people admitted to hospital with ACS received a combination of evidence based medicines, lifestyle advice and referral to cardiac rehabilitation. ${ }^{12}$

Clearly, if WHO global targets are to be met, an overall strengthening of prevention is needed in terms of planning, service delivery and policy. ${ }^{2}$ Initiatives that support primary care to better enable delivery of optimal prevention services are pivotal. ${ }^{3}$ Frequency of attending medical consultations has been found to be associated with compliance with healthcare interventions. ${ }^{13}$ Frequent consultations allow for regular patient-doctor communication and monitoring of disease complications ${ }^{14}$, and influence measures such as morbidity and mortality. ${ }^{15,16} \mathrm{~A}$ report of the Bettering the Evaluation and Care of Health $(B E A C H)$ program in Australia found that $12 \%$ of current problems managed by general practitioners (GPs) are cardiovascular. ${ }^{17}$ An Australian study in a small $(N=108)$ ACS cohort found that the majority of patients visited their GP on at least five occasions (85\%) and a cardiologist at least once $(63 \%)$ in the 12 months after hospital discharge..$^{18}$ The purpose of the present study was to examine the frequency of medical consultations by a large cohort of Australian patients with ACS in the 6 months after hospital discharge, and to determine whether the frequency of medical visits was associated with differences in lifestyle and clinical measures as well as medication prescription.

\section{Methods}

We undertook a subgroup analysis of data collected in the CONCORDANCE registry. CONCORDANCE is an ongoing (prospective) clinical initiative that provides continuous real-time reporting on the clinical characteristics, management and outcomes of patients admitted to Australian hospitals with ACS. ${ }^{19}$ The registry is directed by a national steering committee comprising representatives from participating centres and additional members with expertise in clinical registries, basic science and public health research. ${ }^{19}$ Ethical approval for this subanalysis was obtained from Sydney South West Area Health Service Human Ethics Committee, Concord Hospital zone.

\section{Sites and participants}

CONCORDANCE includes 40 hospitals that are representative of regional and metropolitan acute care facilities, with a range of clinical and treatment characteristics, procedural services and hospital systems. Sites enrol the first 10 patients admitted with a diagnosis of ACS from the beginning of each month who meet the registry inclusion criteria. An opt-out consent process is used to minimise recruitment bias. Discharge lists are screened for records of patients admitted to hospital with suspected ACS to determine those who have died as a result of an ACS event. For inclusion, patients must be older than 18 years and admitted to a participating hospital with a diagnosis of ACS. Patients with an ACS event precipitated by noncardiovascular comorbidity, such as anaemia or trauma, are excluded. 
Patients transferred into, or out of, a registry hospital can be enrolled regardless of the time spent at the transferring institution.

\section{Data collection and outcomes}

Baseline and inhospital data are collected from medical records and entered into a web-based electronic case report form, which includes details of prehospital assessment and management, demographics, admission diagnosis, medical history, in-hospital investigations and management (including referral to cardiac rehabilitation), and in-hospital morbidity and mortality. ${ }^{19}$ At 6 months postdischarge, self-report follow-up is performed via telephone or mail survey with collection of data about vital status, medication compliance, participation in cardiac rehabilitation and CVD risk reduction interventions. ${ }^{19}$ The follow-up includes self-reporting of frequency of medical consultations (GP and cardiologist) in the 6 months after index admission.

\section{Statistical analysis}

We divided patients who were alive and available for follow-up into groups for comparison, based on frequency of GP $(0,1-4, \geq 5)$ and cardiologist $(0,1, \geq 2)$ visits. Patient characteristics, clinical measures, rates of referral to cardiac rehabilitation and provision of guidelinerecommended medications are presented using standard descriptive statistics. Differences in outcome measures between groups were compared using one-way ANOVA for continuous variables (reported as numbers and percentages) and $x^{2}$ test for categorical variables. We used multivariable Poisson regression models to determine the factors associated with the number of visits to a GP and a cardiologist, and derived the incidence rate ratios (IRRs) and corresponding 95\% confidence intervals (Cls).

We identified input variables that were likely to be of clinical importance: age, sex, discharge diagnosis (ST-segment elevation myocardial infarction [STEMI], non-STEMI [NSTEMI] or unstable angina), current smoker, previous vascular disease (including previous myocardial infarction, peripheral arterial disease, transient ischaemic attack or stroke), history of diabetes mellitus, coronary revascularisation during index admission, receipt of cardiac rehabilitation referral and discharged on at least four of the five medications recommended for patients with ACS. In all models, covariates were mutually adjusted, and SAS for Windows 9.4 was used for analyses. A value of $p<0.05$ was considered statistically significant for all analyses.

\section{Results}

At the time of analysis, 6965 patients were registered in CONCORDANCE with an index admission for ACS. Of the 6620 who survived their index hospital admission, 4123 alive patients were successfully contacted at 6 months for follow-up. Excluding patients who did not provide medical visits data, 2755 reported frequency of primary care consultations and 2122 reported frequency of cardiologist consultations in the 6 months since discharge.

Of those who reported GP visits $(N=2755)$, the vast majority (2650/2755, 96\%) visited their GP at least once, and one-third $(964 / 2755,35 \%)$ visited their GP more than five times in the 6-month period. The mean \pm standard deviation (SD) number of GP visits for the cohort was $4.4( \pm 3.8)$ in the 6-month period. The mean \pm SD age was 65 ( \pm 13$)$, the majority were male (1954/2755, 71\%) and most $(2212 / 2755,80 \%)$ had a history of CVD. For frequency of GP visits, there were significant differences between the groups at baseline in terms of their age, sex, medical history, medications prescribed at discharge and referral to cardiac rehabilitation (Table 1). At 6 months follow-up, those who did not see a GP in the 6-month period after discharge had significantly lower rates of participation in cardiac rehabilitation, receipt of dietary advice and prescriptions of cardioprotective medications (Table 1).

In total, 2122 CONCORDANCE participants who survived their index admission were followed up at 6 months after discharge and reported the number of times they had visited a cardiologist in the 6 months after discharge. The mean ( \pm SD) number of cardiologist visits for the cohort was $1.2( \pm 0.9)$ in the 6-month period. Those who were followed up and reported cardiologist visits had a mean $( \pm$ SD) age of $64( \pm 13)$ years; the majority were male (1487/2122, 70\%) and $1702 / 2122(80 \%)$ had a history of CVD. For the number of cardiologist visits, $19 \%$ reported not visiting a cardiologist in the 6 months after discharge, $52 \%$ reported one visit and $29 \%$ reported two or more visits.

When we compared the groups for frequency of cardiologist visits $(0,1, \geq 2)$, there were no significant differences between the groups at baseline in terms of age ( $p=0.083$ ), Global Registry of Acute Coronary Events (GRACE) risk score $(p=0.178)$, history of CVD $(p=0.420)$, previous percutaneous coronary intervention $(\mathrm{PCl})$ or coronary artery bypass graft (CABG) ( $p=0.691)$, aspirin prescribed at discharge $(p=0.076)$ or angiotensin-converting enzyme (ACE) inhibitor/ angiotensin receptor blocker (A2RB) prescribed at discharge $(p=0.052)$ (Table 2). However, at 6 months follow-up, those who did not see a cardiologist in the 6 -month period after discharge had significantly lower rates of participation in cardiac rehabilitation $(p<0.001)$, receipt of dietary advice $(p<0.001)$ and prescriptions of cardioprotective medications aspirin $(p<0.002)$, statins or other lipid-lowering therapy $(p<0.001)$ and ACE/A2RB $(p<0.014)$ (Table 2). 
Table 1. Comparison of frequency of GP consultations in the 6 months after discharge on risk factors and medications in patients with acute coronary syndrome $(N=2755)$

\begin{tabular}{|c|c|c|c|c|c|}
\hline Category & Risk factor or medication & $\begin{array}{l}0 \text { GP visits } \\
(n=105)\end{array}$ & $\begin{array}{c}\text { 1-4 GP visits } \\
(n=1686)\end{array}$ & $\begin{array}{l}\geq 5 \text { GP visits } \\
\quad(n=964)\end{array}$ & $p$ value \\
\hline \multirow{13}{*}{$\begin{array}{l}\text { Demographic and } \\
\text { inpatient information }\end{array}$} & Age, mean \pm SD years & $63 \pm 13$ & $64 \pm 13$ & $66 \pm 13$ & $<0.001$ \\
\hline & Male, $n(\%)$ & $82(78)$ & $1255(74)$ & $617(64)$ & $<0.001$ \\
\hline & GRACE risk, mean $\pm \mathrm{SD}$ & $99.8 \pm 28.1$ & $102.6 \pm 28.6$ & $108.9 \pm 28.6$ & $<0.001$ \\
\hline & History of CVD, $n(\%)$ & $86(82)$ & $1308(78)$ & $818(85)$ & $<0.001$ \\
\hline & History of diabetes, $n(\%)$ & $30(29)$ & $358(21)$ & $316(33)$ & $<0.001$ \\
\hline & Previous PCI or CABG, $n(\%)$ & $30(29)$ & $455(27)$ & $312(32)$ & 0.013 \\
\hline & History of smoking, $n(\%)$ & $36(34)$ & $440(26)$ & $257(27)$ & 0.184 \\
\hline & Inpatient CR referral, $n(\%)$ & $72(69)$ & $1203(71)$ & $601(62)$ & $<0.001$ \\
\hline & Total cholesterol, mean \pm SD mmol/L & $4.5 \pm 1.3$ & $4.7 \pm 1.6$ & $4.5 \pm 2.1$ & 0.346 \\
\hline & LDL cholesterol, mean \pm SD mmol/L & $2.5 \pm 1.2$ & $2.8 \pm 2.2$ & $2.5 \pm 1.0$ & 0.010 \\
\hline & Systolic BP, mean \pm SD mmHg & $142.1 \pm 29.6$ & $140.8 \pm 26.7$ & $140.2 \pm 26.9$ & 0.715 \\
\hline & Diastolic BP, mean \pm SD mmHg & $81.8 \pm 17.5$ & $80.9 \pm 16.8$ & $79.5 \pm 16.6$ & 0.097 \\
\hline & $\mathrm{HbA} 1 \mathrm{c}$, mean $\pm \mathrm{SD}$ & $6.4 \pm 1.6$ & $6.5 \pm 1.7$ & $7.0 \pm 1.8$ & 0.004 \\
\hline \multirow[t]{3}{*}{ Index diagnosis } & STEMI, $n(\%)$ & $24(23)$ & $508(30)$ & $279(29)$ & 0.260 \\
\hline & NSTEMI, $n(\%)$ & $57(54)$ & $797(47)$ & $443(46)$ & 0.259 \\
\hline & Unstable angina, $n(\%)$ & $24(23)$ & $381(23)$ & $242(25)$ & 0.338 \\
\hline \multirow{4}{*}{$\begin{array}{l}\text { Medications at } \\
\text { discharge }\end{array}$} & Aspirin, $n(\%)$ & $89(85)$ & $1461(87)$ & $819(85)$ & 0.427 \\
\hline & Statin/lipid lowering, $n(\%)$ & $95(90)$ & $1571(93)$ & $907(94)$ & 0.321 \\
\hline & Beta-blocker, $n(\%)$ & $69(66)$ & $1296(77)$ & $769(80)$ & 0.003 \\
\hline & ACE/A2RB, $n(\%)$ & $68(65)$ & $1242(74)$ & $732(76)$ & 0.037 \\
\hline \multirow{3}{*}{$\begin{array}{l}\text { 6-month follow-up } \\
\text { data }\end{array}$} & Current smoker, $n(\%)$ & $19(18)$ & $267(16)$ & $139(14)$ & 0.461 \\
\hline & Participated in CR, $n(\%)$ & $27(26)$ & $762(45)$ & $418(43)$ & 0.001 \\
\hline & Received diet advice, $n(\%)$ & $35(35)$ & $947(57)$ & $556(59)$ & $<0.001$ \\
\hline \multirow{4}{*}{$\begin{array}{l}\text { Medications at } \\
6 \text { months }\end{array}$} & Aspirin, $n(\%)$ & $67(64)$ & $1282(76)$ & $704(73)$ & 0.006 \\
\hline & Statin/lipid lowering, $n(\%)$ & $82(80)$ & 1495 (89) & $83(87)$ & 0.007 \\
\hline & Beta-blocker, $n(\%)$ & $56(53)$ & $1154(69)$ & $705(73)$ & $<0.001$ \\
\hline & ACE/A2RB, $n(\%)$ & $67(65)$ & $1182(71)$ & $687(72)$ & 0.324 \\
\hline
\end{tabular}

$\mathrm{A} 2 \mathrm{RB}=$ angiotensin receptor blocker; $\mathrm{ACE}=$ angiotensin-converting enzyme; $\mathrm{BP}=$ blood pressure; $\mathrm{CABG}=$ coronary artery bypass graft; $\mathrm{CR}$ = cardiac rehabilitation; CVD = cardiovascular disease; GP = general practitioner; GRACE = Global Registry of Acute Coronary Events; $\mathrm{HbA1C}$ = glycated haemoglobin; LDL = low-density lipoprotein; NSTEMI = non-ST elevation myocardial infarction; PCI = percutaneous coronary intervention; SD = standard deviation; STEMI = ST elevation myocardial infarction

\section{Factors associated with more frequent medical consultations}

Factors associated with increased frequency of GP and cardiologist visits in the 6 months after index admission are presented in Figure 1. Increased frequency of GP visits was associated with older age, being female, having a diagnosis of STEMI or unstable angina, being a smoker at the time of index admission and having a history of CVD, having a history of diabetes, not undergoing PCI/CABG during the index admission and not receiving a cardiac rehabilitation referral during the index admission (Figure 1). In terms of cardiologist visits, factors associated with increased visit frequency included patients who were either former smokers or had never smoked at the time of index admission and those undergoing PCI/CABG during the index admission
(Figure 1). Factors associated with increased frequency of cardiologist visits included not being a current smoker at the time of index admission and undergoing PCI/CABG during the index admission (Figure 1).

\section{Discussion}

Most ACS survivors in this study saw their GP and a cardiologist at least once during the 6 months after index admission. Not surprisingly, those who saw a GP in the 6-month period after discharge had significantly higher rates of referral to cardiac rehabilitation, receipt of dietary advice and prescription of cardioprotective medications than those who did not see a GP. Statistical modelling suggests that people who are older, female, have a more complex medical history and no preventive 
Table 2. Comparison of frequency of cardiologist consultations in the 6 months after discharge on risk factors and medications in patients with acute coronary syndrome $(N=2122)$

\begin{tabular}{|c|c|c|c|c|c|}
\hline Category & Risk factor or medication & $\begin{array}{c}0 \text { cardiologist } \\
\text { visits } \\
(n=412)\end{array}$ & $\begin{array}{c}1 \text { cardiologist } \\
\text { visit } \\
(n=1099)\end{array}$ & $\begin{array}{c}\geq 2 \text { cardiologist } \\
\text { visits } \\
(n=611)\end{array}$ & $p$ value \\
\hline \multirow{14}{*}{$\begin{array}{l}\text { Demographic and } \\
\text { inpatient information }\end{array}$} & Age, mean $\pm S D$ years & $63 \pm 15$ & $65 \pm 13$ & $64 \pm 12$ & 0.083 \\
\hline & Male, $n(\%)$ & $262(64)$ & $776(71)$ & $449(73)$ & 0.003 \\
\hline & GRACE risk, mean $\pm \mathrm{SD}$ & $101.1 \pm 31.5$ & $103.9 \pm 28.8$ & $104.5 \pm 28.6$ & 0.178 \\
\hline & History of CVD, $n(\%)$ & $340(83)$ & $876(80)$ & $486(80)$ & 0.420 \\
\hline & History of diabetes, $n(\%)$ & $137(33)$ & $272(25)$ & $161(26)$ & 0.004 \\
\hline & Previous PCI or CABG, $n(\%)$ & $130(32)$ & $326(30)$ & $178(29)$ & 0.691 \\
\hline & History of smoking, $n(\%)$ & $139(34)$ & $281(26)$ & $137(22)$ & 0.001 \\
\hline & Inpatient of CR referral, $n(\%)$ & $72(69)$ & $1203(71)$ & $601(62)$ & $<.001$ \\
\hline & Total cholesterol, mean \pm SD mmol/L & $4.5 \pm 1.3$ & $4.7 \pm 1.6$ & $4.5 \pm 2.1$ & 0.346 \\
\hline & LDL cholesterol, mean \pm SD mmol/L & $2.5 \pm 1.2$ & $2.8 \pm 2.2$ & $2.5 \pm 1.0$ & 0.010 \\
\hline & Triglyceride, mean \pm SD mmol/L & $2.1 \pm 1.5$ & $1.9 \pm 1.5$ & $1.8 \pm 1.1$ & 0.015 \\
\hline & Systolic BP, mean \pm SD mmHg & $142.1 \pm 29.6$ & $140.8 \pm 26.7$ & $140.2 \pm 26.9$ & 0.715 \\
\hline & Diastolic BP, mean \pm SD mmHg & $81.8 \pm 17.5$ & $80.9 \pm 16.8$ & $79.5 \pm 16.6$ & 0.097 \\
\hline & $\mathrm{HbA} 1 \mathrm{c}$, mean $\pm \mathrm{SD}$ & $6.4 \pm 1.6$ & $6.5 \pm 1.7$ & $7.0 \pm 1.8$ & 0.004 \\
\hline \multirow[t]{3}{*}{ Index diagnosis } & STEMI, $n(\%)$ & $86(21)$ & $307(28)$ & $195(32)$ & $<.001$ \\
\hline & NSTEMI, $n(\%)$ & $207(50)$ & $506(46)$ & $292(48)$ & 0.335 \\
\hline & Unstable angina, $n(\%)$ & $119(29)$ & $286(26)$ & $124(20)$ & 0.004 \\
\hline \multirow{4}{*}{$\begin{array}{l}\text { Medications at } \\
\text { discharge }\end{array}$} & Aspirin, $n(\%)$ & $371(90)$ & $1028(94)$ & 560 (92) & 0.076 \\
\hline & Statin/lipid lowering, $n(\%)$ & $376(91)$ & $1036(94)$ & 579 (95) & 0.074 \\
\hline & Beta-blocker, $n(\%)$ & $299(73)$ & $851(77)$ & $491(80)$ & 0.017 \\
\hline & ACE/A2RB, $n(\%)$ & $308(75)$ & $841(77)$ & $435(71)$ & 0.052 \\
\hline \multirow{3}{*}{$\begin{array}{l}\text { 6-month follow-up } \\
\text { data }\end{array}$} & Current smoker, n (\%) & $97(24)$ & $154(14)$ & $70(11)$ & $<0.001$ \\
\hline & Participated in CR, $n(\%)$ & $102(25)$ & $489(45)$ & $304(50)$ & $<0.001$ \\
\hline & Received diet advice, n (\%) & $192(48)$ & $592(56)$ & 357 (61) & $<0.001$ \\
\hline \multirow{4}{*}{$\begin{array}{l}\text { Medications at } \\
6 \text { months }\end{array}$} & Aspirin, $n(\%)$ & $333(81)$ & $964(88)$ & $518(85)$ & 0.002 \\
\hline & Statin/lipid lowering, $n(\%)$ & $335(83)$ & 987 (91) & $550(91)$ & $<0.001$ \\
\hline & Beta-blocker, $n(\%)$ & $272(67)$ & 755 (69) & $443(73)$ & 0.109 \\
\hline & ACE/A2RB, $n(\%)$ & $266(66)$ & 799 (74) & $419(69)$ & 0.014 \\
\hline
\end{tabular}

$\mathrm{A} 2 \mathrm{RB}=$ angiotensin receptor blocker; $\mathrm{ACE}=$ angiotensin-converting enzyme; $\mathrm{BP}=$ blood pressure; $\mathrm{CABG}=$ coronary artery bypass graft; $C R=$ cardiac rehabilitation; CVD = cardiovascular disease; GRACE = Global Registry of Acute Coronary Events; HbA1c = glycated haemoglobin; LDL = low-density lipoprotein; NSTEMI = non-ST elevation myocardial infarction; $\mathrm{PCl}$ = percutaneous coronary intervention; SD = standard deviation; STEMI = ST elevation myocardial infarction

strategy are more likely to see their GP more frequently. As anticipated, patients with ACS who undergo coronary revascularisation during their index admission are more likely to see a cardiologist after discharge.

Frequency of medical visits is not a comprehensive measure of CVD-related consultations, nor is it a measure of the quality of care received; however, it does give an indication of potential opportunities to influence preventive care. A large retrospective cohort study ( $N=31841)$ based on data from Western Australia found regular GP visits offer a small but significant protection against morbidity and all-cause mortality in older people with established ischaemic heart disease (IHD). ${ }^{16}$ In that study's cohort, the mean number of GP visits per person per year was $9.9( \pm 6.7)$ and, compared with the least regular quartile, patients with greater regularity of GP visits had significantly decreased risks of all-cause death (2nd least, 2nd most and most regular: hazard ratio $(H R)=0.76,0.71$ and 0.71 respectively) and $I H D$ death (2nd least, 2nd most and most regular: $\mathrm{HR}=0.70,0.68$ and 0.65 respectively). Patients in the 2 nd least regular quartile also appeared to experience decreased risk of any repeat IHD hospitalisation (HR0.83; 95\% CI 0.71, 0.96 ) and emergency hospitalisation (HR0.81; $95 \% \mathrm{Cl}$ $0.67,0.98)$, compared with the least regular quartile. ${ }^{16}$ The same research group also demonstrated similar results in a large Australian cohort $(N=108455)$ with chronic respiratory disease, and the authors concluded 
Figure 1. Multiple-adjusted incidence rate ratios and corresponding $95 \%$ confidence intervals for visits to a GP and a cardiologist

\section{Visits to GP}

Age: $55-64$ vs $18-54$

Age: $65-73$ vs $18-55$

Age: $\geq 74$ vs $18-49$

Male vs female

STEMI vs NSTEMI

UA vs NSTEMI

Current smoker vs ex/never

History of CVD vs not

History of diabetes vs not

In-hospital PCI/CABG vs not

Receipt of cardiac rehabilitation referral vs not

4 of 5 medications vs $<4$ medications

\section{Visits to cardiologist}

Age: $55-64$ vs $18-54$

Age: $65-73$ vs $18-55$

Age: $\geq 74$ vs $18-49$

Male vs female

STEMI vs NSTEMI

UA vs NSTEMI

Current smoker vs ex/never

History of CVD vs not

History of diabetes vs not

In-hospital PCI/CABG vs not

Receipt of cardiac rehabilitation referral vs not

4 of 5 medications vs $<4$ medications

$$
0.7
$$

Incidence rate ratio $(95 \% \mathrm{Cl})$

$p$ value

$0.96(0.91,1.02)$

0.0004

$1.05(0.99,1.11)$

$1.07(1.01,1.14)$

$0.84(0.81,0.88)<0.0001$

$1.08(1.04,1.13) \quad 0.0002$

$1.07(1.03,1.13)$

$1.09(1.05,1.15) \quad 0.0001$

$1.06(1.01,1.12) \quad 0.0214$

$1.26(1.21,1.31)<0.0001$

$0.95(0.91,0.99) \quad 0.0178$

$0.93(0.89,0.97) \quad 0.0006$

$1.03(0.99,1.08) \quad 0.1290$

$1.08(0.96,1.21) \quad 0.5074$

$1.03(0.92,1.17)$

$1.01(0.89,1.14)$

$1.09(0.99,1.19) \quad 0.0654$

$1.06(0.97,1.17) \quad 0.3325$

$0.97(0.88,1.08)$

$0.83(0.75,0.92) \quad 0.0003$

$0.99(0.89,1.09) \quad 0.8033$

$0.97 \quad(0.88,1.06) \quad 0.4994$

$1.15(1.05,1.26) \quad 0.0028$

$1.07(0.98,1.19) \quad 0.1304$

$1.04(0.95,1.15) \quad 0.4031$

$\mathrm{CABG}=$ coronary artery bypass graft surgery; $\mathrm{Cl}=$ confidence interval; CVD = cardiovascular disease; GP = general practitioner;

NSTEMI = non-ST elevation myocardial infarction; $\mathrm{PCl}=$ percutaneous coronary intervention; STEMI = ST elevation myocardial infarction; $\mathrm{UA}=$ unstable anqina

that regular and proactive primary care (as distinct from 'reactive' care) was beneficial to older patients with respiratory disease by reducing their risks of hospitalisation and death. ${ }^{10}$

In the current study, we found the mean number of GP consultations was 4.4 in 6 months, and that increased frequency of visits was associated with a cardiac rehabilitation referral. This suggests that initiating appropriate prevention before hospital discharge may facilitate more regular GP visits and consequently improve outcomes. Furthermore, an Australian study suggests that the combination of medical visits and a secondary prevention program may give the best outcomes. ${ }^{3,18}$

Increased frequency of medical consultations is likely to be associated with greater rapport building and, importantly, shared decision making in CVD prevention (which has been found to improve patient satisfaction and involvement in medical consultations). ${ }^{21}$ Active engagement of patients is particularly important for survivors of ACS, who are often expected to make multiple concurrent changes to risk factors and maintain them in the long term. ${ }^{21,22}$ More frequent medical consultations also provide more opportunity to review test results and medications, and compare progress with agreed targets, while also providing psychosocial support. ${ }^{16}$ The opportunity to focus on maintenance of a healthy lifestyle is also increased when patients have regular appointments with a GP, which is likely to increase compliance with secondary prevention strategies and in turn improve mortality and morbidity. ${ }^{16,23}$

This study has some limitations. Most importantly, this is a subgroup analysis of a registry cohort, and data were collected from medical records at baseline 
and via self-report (telephone and mail survey) at six months. Missing data was unavoidable, either because the information was not recorded in the medical records or patients did not provide data via survey or telephone. Also, data were collected based on hospital admissions for only the first 10 consecutive patients who met the inclusion criteria each month within hospitals, and this may not be representative of admissions over the entire calendar year. As this was a substudy, we could not analyse other possible factors such as depression because it was not collected in the registry. Further, this study did not incorporate clinical measures (such as cholesterol levels) when determining the likelihood of the higher medical visit frequency due to the lack of power. In addition, the exact nature of communication management within each consultation was not investigated in this study. However, we have established that ACS survivors do consult their doctors regularly; therefore, there is a need to maximise the opportunity at each consultation to ensure that ongoing prevention is a regular topic of discussion. Because this study is a subgroup analysis, it is hypothesis generating; future research could formally test associations and examine the impact of initiatives that aim to strengthen the quality and value of medical consultations.

\section{Conclusion}

Most of the ACS survivors in this study saw their GP frequently and their cardiologist at least once during the 6 months after index admission. Therefore, there is ample opportunity for doctors to facilitate optimal risk factor reduction and medication prescriptions. Patients who were not referred to cardiac rehabilitation were more likely to visit GPs, possibly due to further illness. This highlights the importance of implementing services that ensure preventive strategies are in place at the point of discharge (if not before)

Our research found that referral to cardiac rehabilitation has a significant association with medical visit frequency, but further research is needed to clarify the impact of cardiac rehabilitation referral or attendance and medical visit frequency, and vice versa. Capitalising on these opportunities is likely to strengthen prevention in primary care and ultimately contribute to better outcomes for people with heart disease.

\section{Acknowledgements}

$\mathrm{KH}$ is funded by a Cardiac Society of Australia and New Zealand postgraduate research scholarship. CKC is funded by a career development fellowship cofunded by the National Health and Medical Research Council, the National Heart Foundation and the Sydney Medical Foundation Chapman Fellowship. KS is funded by a University of Sydney international postgraduate scholarship. JR is funded by a career development and future leader fellowship cofunded by the National Health and Medical Research Council and the National Heart Foundation. JR and CKC are investigators on NHMRC program grant ID1052555.

\section{Competing interests}

CONCORDANCE is supported by unrestricted educational grants from Sanofi-Aventis; the Merck, Sharp and Dohme/Schering-Plough joint venture; Eli Lilly; AstraZeneca; Boehringer Ingelheim; the National Heart Foundation of Australia; and the National Health and Medical Research Council postgraduate scholarship funding program. These funds have been distributed between project coordination and database management, and provision of per-patient payments to participating sites. Pharmaceutical sponsors receive periodic reports on the use of therapies from aggregate data, de-identified for hospital, physician and patient.

\section{Author contributions}

$\mathrm{KH}$, JR and DB conceived the research and led the concept development, analysis and interpretation. $\mathrm{MI}, \mathrm{DA}, \mathrm{KA}, \mathrm{PRT}$ and DB are senior investigators on CONCORDANCE and have had extensive involvement in the registry in terms of design, data collection and analysis. CC, KS and EA provided intellectual contributions in terms of design and interpretation. All authors reviewed and approved the final manuscript.

\section{References}

1. World Health Organization. Global action plan for the prevention and control of NCDs 2013-2020. Geneva: WHO; 2013 [cited 2015 Nov 12]. Available from: www.who.int/nmh/events/ncd_action_plan/en

2. Perel P, Avezum A, Huffman M, Pais P, Rodgers A, Vedanthan $\mathrm{R}$, et al. Reducing premature cardiovascular morbidity and mortality in people with atherosclerotic vascular disease: The World Heart Federation roadmap for secondary prevention of cardiovascular disease. Glob Heart. 2015;10(2):99-110.

3. Redfern J, Chow C. Strengthening preventive cardiology. Heart Lung Circ. 2014;24(5):427-9.

4. The Department of Health. Cardiovascular disease. Canberra: Australian Government; 2015 [cited 2015 Oct 27]. Available from: www.health.gov.au/internet/ main/publishing.nsf/content/chronic-cardio

5. Task force on the management of ST-segment elevation acute myocardial infarction of the European Society of Cardiology (ESC), Steg PG, James SK, Atar D, Badano LP, Blömstrom-Lundqvist C, et al. ESC guidelines for the management of acute myocardial infarction in patients presenting with ST segment elevation. Eur Heart J. 2012;33(20):2569-619. 
6. Anderson JL, Adams CD, Antman EM, Bridges CR, Califf RM, Casey DE Jr, et al. 2011 ACCF/AHA focused update incorporated into the ACC/AHA 2007 guidelines for the management of patients with unstable angina/ non-ST-elevation myocardial infarction: a report of the American College of Cardiology Foundation/American Heart Association Task Force on Practice Guidelines. Circulation. 2011;123(18):e426-579.

7. Aroney CN, Aylward P, Kelly AM, Chew DPB, Clune E, on behalf of the Acute Coronary Syndrome Guidelines Working Group. Guidelines for the management of acute coronary syndromes 2006. Med J Aust. 2006;184(8): 1-32.

8. National Heart Foundation of Australia, Cardiac Society of Australia and New Zealand. Reducing risk in heart disease. An expert guide to clinical practice for secondary prevention of coronary heart disease. Canberra: National Heart Foundation of Australia; 2012 [cited 2015 Oct 23]. Available from: heartfoundation.org. au/images/uploads/publications/Reducing-risk-in-heartdisease.pdf

9. Gislason GH, Rasmussen JN, Abildstrøm SZ, Gadsbø\|l N, Buch $\mathrm{P}$, Friberg J, et al. Long-term compliance with beta-blockers, angiotensin-converting enzyme inhibitors, and statins after acute myocardial infarction. Eur Heart $\mathrm{J}$. 2006;27(10):1153-8.

10. Chow CK, Jolly S, Rao-Melacini P, Fox KA, Anand SS, Yusuf S. Association of diet, exercise, and smoking modification with risk of early cardiovascular events after acute coronary syndromes. Circulation. 2010;121(6):750-8.

11. Suaya JA, Shepard DS, Normand SL, Ades PA, Prottas J, Stason WB. Use of cardiac rehabilitation by Medicare beneficiaries after myocardial infarction or coronary bypass surgery. Circulation. 2007;116(15):1653-62.

12. Redfern J, Hyun K, Chew DP, Astley C, Chow C, Aliprandi-Costa B, et al. Prescription of secondary prevention medications, lifestyle advice and referral to rehabilitation among acute coronary syndrome (ACS) inpatients: results from a large prospective audit in Australia and New Zealand. Heart. 2014;100(16):1281-8.

13. Macharia WM, Leon G, Rowe BH, Stephenson BJ, Haynes RB. An overview of interventions to improve compliance with appointment keeping for medical services. JAMA. 1992;267(13):1813-7.

14. Knuiman MW, Welborn TA, Bartholomew HC. Selfreported health and use of health services: a comparison of diabetic and nondiabetic persons from a national sample. Aust N Z J Public Health. 1996;20(3):241-7.
15. Ayanian JZ, Landrum MB, Guadagnoli E, Gaccione P. Specialty of ambulatory care physicians and mortality among elderly patients after myocardial infarction. New Engl J Med. 2002;347(21):1678-86.

16. Einarsdottir K, Preen DB, Emery JD, Holman CDJ. Regular primary care plays a significant role in secondary prevention of ischemic heart disease in a Western Australian cohort. J Gen Int Med. 2011;26(10):1092-7.

17. Britt $\mathrm{H}$, Miller GC, Charles J, Pan Y, Valenti L, Henderson J, et al. General practice activity in Australia 2005-2006. Canberra: Australian Institute of Health and Welfare, University of Sydney; 2007 [cited 2015 Nov 12] Available from: www.aihw.gov.au/WorkArea/ DownloadAsset.aspx?id=6442456145

18. Redfern J, Menzies M, Briffa, Freedman SB. Impact of medical consultation frequency on modifiable risk factors and medications at 12 months after acute coronary syndrome in the $\mathrm{CHOICE}$ randomised controlled trial. Int J Cardiol. 2010;145(3):481-6.

19. Aliprandi-Costa B, Ranasinghe I, Turnbull F, Brown A, Kritharides $L$, Patel $A$, et al. The design and rationale of the Australian Cooperative National Registry of Acute Coronary care, Guideline Adherence and Clinical Events (CONCORDANCE). Heart Lung Circ. 2013;22(7):533-41.

20. Einarsdóttir K, Preen DB, Emery JD, Kelman C, Holman CDJ. Regular primary care lowers hospitalisation risk and mortality in seniors with chronic respiratory diseases. J Gen Int Med. 2010;25(8):766-73.

21. Krones T, Keller H, Sonnichsen A, Sadowski EM, Baum E, Wegscheider K, et al. Absolute cardiovascular disease risk and shared decision making in primary care: a randomized controlled trial. Ann Fam Med. 2008;6(3):218-27.

22. Toren O, Kerzman H, Koren N, Baron-Epel O. Patients' knowledge regarding medication therapy and the association with health service utilization. Eur J Cardiovasc Nurs. 2006;5(4):311-6.

23. Hedback B, Perk J, Wodlin P. Long-term reduction of cardiac mortality after myocardial infarction: 10-year results of a comprehensive rehabilitation programme. Eur Heart J. 1993;14(6):831-5.

\section{Copyright: (c) (i) (2) (2)}

(C) 2016 Hyun et al. This article is licensed under the Creative Commons Attribution-NonCommercial-ShareAlike 4.0 International Licence, which allows others to redistribute, adapt and share this work non-commercially provided they attribute the work and any adapted version of it is distributed under the same Creative Commons licence terms. See: www.creativecommons.org/licenses/by-nc-sa/4.0/ 